\title{
Assessment of three solar-assisted heat pump typologies in Canada: parallel, series, and ice storage
}

\author{
Benjamin Beauchamp ${ }^{1,2 *}$, Sébastien Brideau ${ }^{1}$, and Cynthia Cruickshank ${ }^{2}$ \\ ${ }^{1}$ Natural Resources Canada, CanmetENERGY, 1 Haanel Drive, Ottawa ON, K1A 1M1, Canada \\ ${ }^{2}$ Carleton University, Department of Mechanical and Aerospace Engineering, 1125 Colonel By Drive, Ottawa ON, K1S 5B6, Canada
}

\begin{abstract}
This paper discusses the energy savings, operating costs, and net present values of three typologies of solar assisted heat pump in Canada: parallel systems, series systems, and ice storage systems. Typologies are evaluated for three detached house archetypes of varying energy performances, and across a variety of Canadian climates. Hourly energy modelling is accomplished with a custom spreadsheet tool. The models developed are approximate and meant for high level analysis. This work is meant as a first step in a process of verifying the potential for each of the typologies. In most cases, the parallel system performs best in terms of annual energy savings. The paper goes over the models, assumptions, and some results. Recommendations are discussed for future research focusing on system payback times. The next step will consist of using a detailed sub-hourly simulation tool for the typology that has been found to be the most promising.
\end{abstract}

\section{Introduction}

Residential sector space heating, cooling and domestic hot water loads account for a significant portion of energy consumption globally, including $13.6 \%$ in Canada, 2016[1]. This consumption is highest in developed countries, where the energy for these end-uses is typically sourced from electricity and natural gas [2]. To reduce energy demand and associated greenhouse gas (GHG) emissions, alternative methods of heating are needed. Airsource heat pump (ASHP) and cold-climate air-source heat pump (CCASHP) systems are examples of technologies whose markets have been consistently growing in size [3]. ASHP and CCASHP systems can operate at a higher coefficient of performance (COP) than resistance heating in many conditions. However, their COP is lowest in the cold winter air when space heating demand is highest. The integration of solar sourced heat with CCASHPs has potential to address this issue. On cold but sunny days, a solar-assisted heat pump (SAHP) can capture more free energy than a CCASHP [4]. A collector bank is used to capture heat, which can then be used in a variety of ways in conjunction with a heat pump to heat the space. Specifically, the collectors can be used to increase the heat pump's COP or to decrease the amount of work that the heat pump's compressor must do. There are many possible configurations of SAHP though no comparative analysis of these configurations has ever been done for Canadian climates and economic situation.

The Canadian federal and provincial governments recently set aspirational performance targets for high performance heat pump technology and heating systems integrated with renewable technologies [5]. To meet these goals, heating systems should be assessed for market and energy performance potential. The aim of this paper is to present a high-level analysis of three SAHP configurations, to find which holds the most potential in cold-climate conditions. The base components of most systems are the heat pump, an array of flat-plate solar collectors, and the storage tank. The heat pump and solar collectors can be connected in series, in parallel, or in some combination of both.

There is existing simulation work broadly comparing topologies that is useful to consider. However, much of this work is dated or not specific to cold climates. Freeman et al. [4] compared the performance of several configurations in Wisconsin and New Mexico, 1979. They found that parallel configurations outperformed series and solar-only thermal systems. The reason for these results is that the parallel system can use available solar resource without the use of the heat pump. The heat pump is only used when it is needed and beneficial. In contrast, the series system must run the heat pump (which requires considerable power) whenever the collectors are in operation [6,7]. This can be addressed by adding complexity to the system in the form of a bypass loop, however more complex controls are needed.

Heat pump technology has improved greatly over the last 30 years, so analysis with high performance heat pumps in Canada is required. A paper by Carbonell et al [8] indicated Davos as an optimal European climate for SAHP due to its combination of high irradiance and heating demand. Many Canadian cities have irradiances

\footnotetext{
* Corresponding author: BenBeauchamp@cmail.carleton.ca
} 
and heating demands similar to or higher than those seen in Davos, so it is reasonable to think that SAHP would perform equally well in those conditions.

\section{Description of Topologies}

This section will outline the three simulated topologies. Their modes of operation will be described, accompanied by system schematics.

\subsection{Series}

In a series configuration the heat pump sources heat directly from the solar collectors as shown in Fig. 1. Fluid is pumped through a flat plate collector array to the heat pump's evaporator. A compressor then upgrades the heat to a storage tank. For this work, the main storage tank does not exceed $60^{\circ} \mathrm{C}$ due to limitations of the heat pump. Heat from the tank is used to meet the space heating load whenever possible, a backup resistance heater meets the remaining load. Domestic water from the mains flows through a heat exchanger in the HW-ST. The water is then sent to a separate DHW tank which, for this analysis, is maintained at $55^{\circ} \mathrm{C}$ by an auxiliary electric resistance heater. Any portion of the space heating load that is not met by the heat pump is met by a backup resistance heater, which delivers heat directly to the air handling unit.

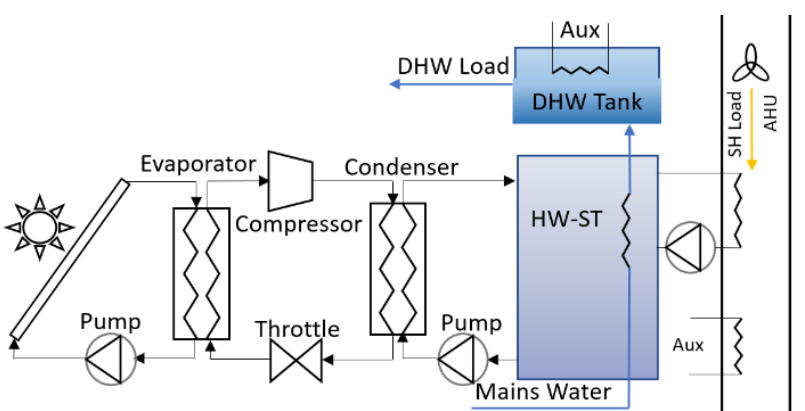

Figure 1. Series System Topology

\subsection{Parallel}

In a parallel configuration the collector and heat pump are separate loops. The solar thermal loop is shown, connected to the hot water storage tank (HW-ST) in Fig 1. Fluid is pumped through a solar collector array to a storage tank. In this analysis, the maximum temperature of the HW-ST was $70^{\circ} \mathrm{C}$. A heat exchanger connected to the tank delivers heat to the space. Next, domestic water from the mains flows through a heat exchanger in the HW-ST. The water is then sent to a separate DHW tank which is, for this analysis, maintained at $55^{\circ} \mathrm{C}$ by an auxiliary electric resistance heater. If the HW-ST is depleted and there is a call for heat, the heat pump loop takes heat from the outside air and upgrades it for space heating. Any portion of the space heating load that is not met by the heat pump or HW-ST is met by a backup resistance heater.

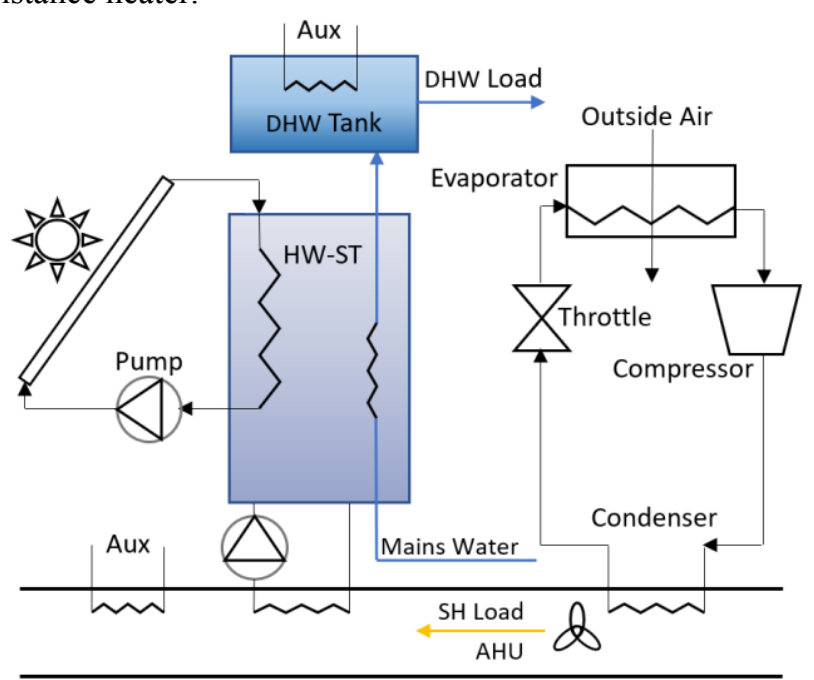

Figure 2. Parallel System Topology

\section{$2.3 \quad$ Ice storage}

The ice storage system is best classified as a combination of a modified series configuration and a direct solar thermal loop. The solar thermal loop uses heat from the collectors to meet the space heating load directly, bypassing the tank, whenever possible. When collector temperatures are lower but net heat gain is still positive, the heat is instead used to charge the tank. A liquid-toliquid heat pump is used to heat the space or the DHW tank. The heat pump draws heat from the ice storage tank. The benefit of the ice storage tank is that the heat pump has a steady $0^{\circ}$ Celsius source to draw from. The solar collectors are used to either add heat to the tank, or to directly heat the house. The ice-storage tank can reach a maximum temperature of $60^{\circ} \mathrm{C}$ when heated with solar heat. For this high-level analysis, it is assumed that the heat pump is able to source the heat at this high temperature, which is above typical temperature ranges for these types of heat pumps (either by reducing water flow rate to the heat pump, or with a water recirculation valve, neither of which are shown in Fig. 3). The temperature of the ice storage tank generally remains around $0^{\circ} \mathrm{C}$ during the winter months, and only gets to high temperatures later during the shoulder seasons and summer. Backup resistance heaters are used to meet any remaining unmet $\mathrm{SH}$ and DHW load.

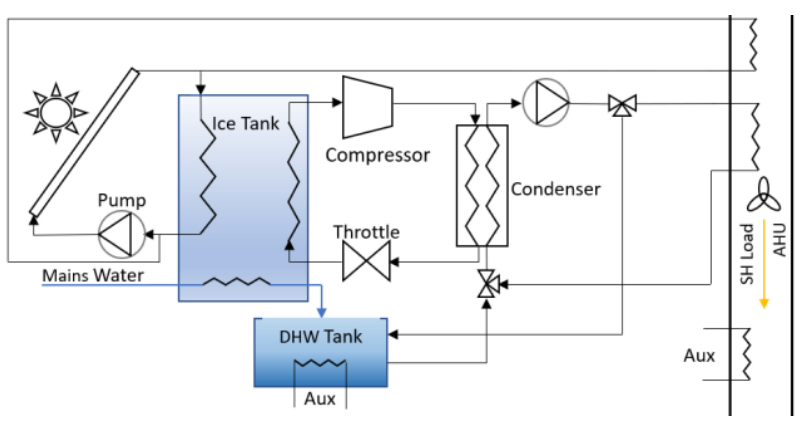

Figure 3. Ice Storage Topology 


\section{Description of Modelling}

Excel was used to write custom simplified hourly models of the systems, and run simulations for the purpose of high-level comparison. Many assumptions were required to simplify the analysis (further explained below), and more detailed modelling will be performed in the future with a sub-hourly building simulation tool. For this work, the hourly weather data used is Canadian Weather Year for Energy Calculation (CWEC) data [9]. For each archetype and climate, hourly space heating loads were previously estimated from monthly HOT2000 simulation [10] results and hourly CWEC data using a methodology developed for that purpose [11].

The $2.9 \mathrm{~m}^{2}$ collectors are vertical with a tilt angle of $90^{\circ}$ and are south facing. This angle was chosen to maximize the captured solar in the winter, while minimizing collector overheating in the summer. An analysis found that the annual energy consumption of the systems was fairly insensitive to tilt angle between $45^{\circ}$ and $90^{\circ}$ (vertical) with a range of less than 0.3 GJ. The amount incident on the tilted collectors is calculated using equation 1.

$$
I_{\text {Tilt }}=I_{b} R_{b}+I_{d}\left(1+\frac{\cos \beta}{2}\right)+I_{\rho} 0.6\left(1-\frac{\cos \beta}{2}\right)
$$

Once the amount of incident solar radiation is calculated, the collector output is calculated. Collector efficiency is calculated according to equation 2 .

$$
\begin{aligned}
\eta=0.717 & -4.0141\left(\frac{T_{\text {in }}-T_{\text {out }}}{I}\right) \\
& -0.01872\left(\frac{\left(T_{\text {in }}-T_{\text {out }}\right)^{2}}{I}\right)
\end{aligned}
$$

The HW-ST is modelled using a single node. Tank losses are calculated assuming a constant surrounding temperature. The energy balance in the tank is recalculated each timestep according to equation 3 for water tank (ice storage accounts for latent heat of fusion, not shown here). All heat exchangers are assumed to have an effectiveness of one. The series and ice storage system use the same water-to-water heat pump normalized performance map. The parallel and CCASHP base case share the same air-to-air heat pump normalized performance map.

$E_{s t}=m C_{p} \frac{d T}{d x}=E_{\text {in }}-E_{\text {out }}-U A_{\text {tank }}\left(T-T_{\text {room }}\right)$

Costing of energy is taken from the reference case of the Canada Energy Regulator's energy forecast [12]. Additionally, all cases are considered to have a flat rate energy cost based on todays rates (i.e., not time-of-use or tiered pricing). The NPV considers both the operating cost savings provided by the system and its capital cost. For this analysis, calculation of the NPV assumes a 20-year system lifespan. The Utility Forecast used in the NPV calculation is based on the current economic and energy policy outlook. If energy prices were to escalate more over the 20-year period, this would be a net benefit to the SAHP systems. Capital costs come from a variety of sources (online and cost estimates of previous projects). The uncertainty of the capital costs are likely very high, and future work will attempt to get more accurate estimates of these costs.

Table 1- Electricity Cost by City

\begin{tabular}{|l|l|l|l|}
\hline City & MON & WIN & TOR \\
\hline Electricity Cost $(\$ / \mathrm{kWh})$ & 0.11 & 0.12 & 0.25 \\
\hline
\end{tabular}

\section{System Sizing}

In order to approach an optimal sizing for the configurations, the impact of three factors were considered. The size of the hot water storage tank, the nominal capacity of the heat pump, and the number of collectors were the component sizes considered. Initial values considered were based on guidelines or calculated from datasets of designs compiled by the International Energy Agency Solar Heating and Cooling programme Task44 [13]. Factor $\mathrm{A}$ is the ratio of tank volume to collector area and was found to be approximately $0.06 \mathrm{~m}$ for many typical designs, so it was considered as a starting point for tank sizing. Second, the ratio of collector area to heat pump capacity (factor B) was found to vary between 0.5 and $1.5 \mathrm{~m}^{2} / \mathrm{kW}$ for flat plate collectors, so $1 \mathrm{~m}^{2} / \mathrm{kW}$ was used as a starting point for heat pump sizing. The final factor considered is the number of collectors (factor $\mathrm{C}$ ), which was initially set to 6 as a starting point. These factors can be varied while holding the others constant, to indicate whether the topologies are either already sized accurately at the original ratios or that the topologies are insensitive to these factors.

Initial simulations were run using Montreal data and a pre-1980 Canadian housing archetype representing a residence with high heating demand, unless otherwise stated. This archetype was chosen because higher overall load values more clearly indicate the sizing trends.

\subsection{Series Sizing}

The series system was found to be generally insensitive to Factor A (storage volume/collector area), very sensitive to Factor B (collector area/heat pump capacity), and moderately sensitive to collector area. This sensitivity to Factor B is expected because a limitation of the simple series topology is that they must run the heat pump to access solar resource. This means that there is a optimal sizing of the heat pump in terms of energy consumption, unlike other topologies which yield diminishing returns.

Factor A was varied from $0.045-0.2 \mathrm{~m}$. Annual energy consumption reached a minimum near a tank volume of $1.3 \mathrm{~m}^{3}$ at a factor $\mathrm{A}$ value of $0.075 \mathrm{~m}$. Both series and parallel topologies share this quality of an optimal storage size, as shown in Fig. 4. Varying factor B 
indicated that the annual energy consumption is minimized at a nominal capacity of $6.9 \mathrm{~kW}$ at a factor B value of $2.5 \mathrm{~m}^{2} / \mathrm{kW}$ for the pre-80s housing archetype. However, due to the system's sensitivity to heat pump capacity, the size is changed between archetypes to 5.75 $\mathrm{kW}$ (Factor $\mathrm{B}=3.0 \mathrm{~m}^{2} / \mathrm{kW}$ ) for the Post-80s housing and $2.3 \mathrm{~kW}$ (Factor $\mathrm{B}=7.5 \mathrm{~m}^{2} / \mathrm{kW}$ ) for the NZE housing.

Data from real designs reported in [13] shows that for SAHP systems similar to those discussed here, most systems have collector area to total heat demand ratios of between 0.5 to $1.0 \mathrm{~m}^{2} / \mathrm{MWh}$, which is equivalent to around 2-7 collectors across the three cities depending on heating demand for a post-1980s residence. This estimate is reinforced by an analysis of energy use and cost factors which indicated diminishing returns with more than 6 collectors. For the purposes of this work, 6 collectors were used initially.

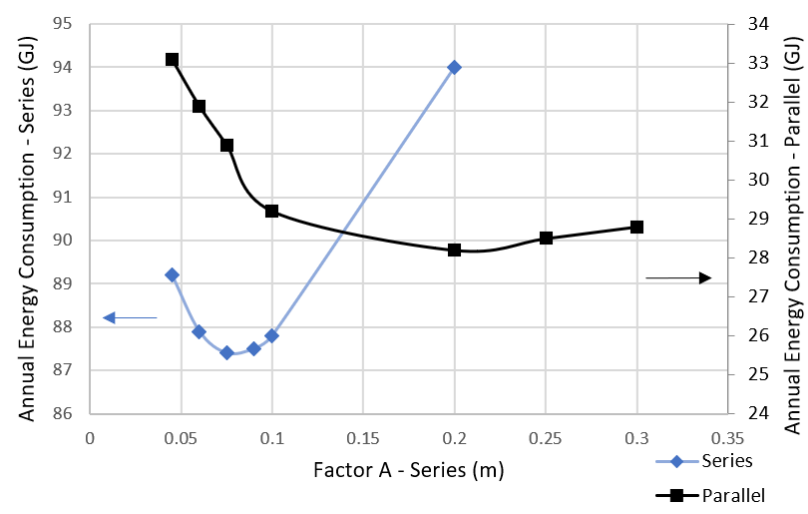

Figure 4. Trend of Energy Consumption with Storage Size (Montreal, Pre 80`s, 6 collectors)

\subsection{Parallel Sizing}

For the parallel topology, the annual energy consumption was found to be generally insensitive to Factor A and Factor B. The system was found to be very sensitive to collector area.

Like the series system, a minimum exists for the storage, around a tank volume of $4.3 \mathrm{~m}^{3}$ at $0.2 \mathrm{~m}$. However, such a large tank would be infeasible for many residences. For the purposes of this paper, a more standard $1 \mathrm{~m}^{3}$ tank will be used. The difference in heat pump sizing trends is shown in Fig. 5, for 6 collectors $\left(17.2 \mathrm{~m}^{2}\right)$. The series system is varied from a Factor B of $5 \mathrm{~m}^{2} / \mathrm{kW}(3.5$ $\mathrm{kW}$ capacity heat pump) to $0.5 \mathrm{~m}^{2} / \mathrm{kW}(35 \mathrm{~kW})$. A Factor $\mathrm{B}$ of 5 results in an oversized $35 \mathrm{~kW}$ heat pump, resulting in a significant increase in annual energy consumption. Unlike the series topology, increasing the heat pump capacity of the parallel topology provides benefits with diminishing returns up to $35 \mathrm{~kW}$. However, such a large heat pump would also be impractical from a cost perspective, while the increase in energy savings is marginal, so a more standard $11.5 \mathrm{~kW}$ (Factor B of 1.5) capacity heat pump will be used. Unlike the series topology, the heat pump capacity is not varied between archetypes. For comparison, the CCASHP is also simulated using an $11.5 \mathrm{~kW}$ heat pump. For the reasons described in the series topology, 6 collectors will be used.

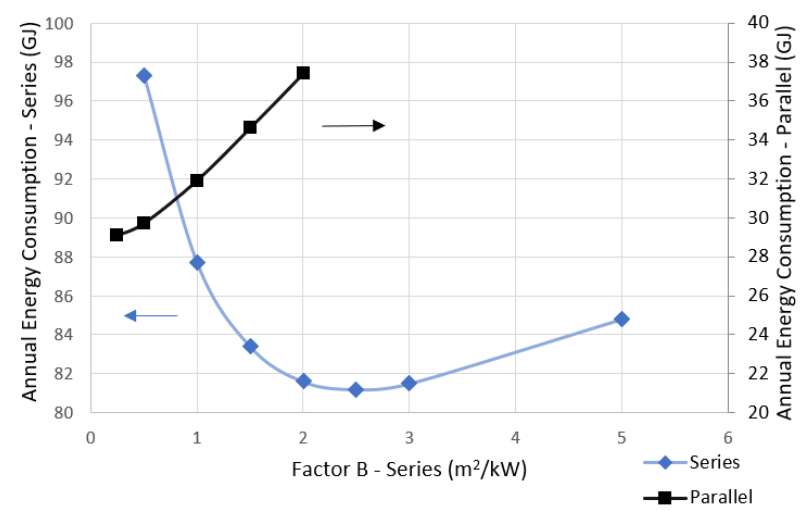

Figure 5. Trend of Energy Consumption with Heat Pump Capacity (Montreal, Pre 80's, 6 Collectors)

\subsection{Ice Tank System Sizing}

The ice tank topology is organized similarly to the parallel system. The direct solar thermal loop has a large impact on sizing. The ice tank system was found to share very similar sizing trends as the parallel system, though exaggerated to a greater degree. The system has very little sensitivity to storage tank size (Factor A variation) and heat pump capacity (Factor B variation), while being extremely sensitive to collector area (Factor $\mathrm{C}$ variation).

Due to the system's insensitivity, the system was simulated using an $11.5 \mathrm{~kW}$ heat pump and $1 \mathrm{~m}^{3}$ storage tank, like the parallel system. For the reasons described regarding the series topology, 6 collectors will be used.

As mentioned in the series section, the number of collectors used is dependent on the ratio of the total area to the heating load in MWh. However, the load varies significantly between archetypes as shown in Table 1 . Importantly, the change in load between the Post-1980s residence to a NZE residence indicates that 1-3 collectors would be more suitable in the NZE case. While 6 collectors were used for the main analysis, simulations using 3 collectors in the NZE residence archetype were also performed and the effects on performance discussed.

Table 2. Annual Heating Demand by City

\begin{tabular}{|l|c|c|}
\hline City & $\begin{array}{l}\text { Post-1980s } \\
(\mathrm{MWh})\end{array}$ & NZE (MWh) \\
\hline Montreal & 14.6 & 5.0 \\
\hline Winnipeg & 20.1 & 7.1 \\
\hline Toronto & 12.8 & 4.3 \\
\hline
\end{tabular}

\section{Results}

This section will present the simulation results for the three topologies in terms of annual energy savings, annual operating cost (AOC), and net present value (NPV). The $\mathrm{AOC}$ is calculated using the cost of electricity (variable cost) and the base monthly connection fee (fixed cost). The results are compared using the CCASHP as a base 
case. The numerical results of the CCASHP are below in Table 2.

Table 3. CCASHP Simulation Results

\begin{tabular}{|l|l|r|r|r|}
\hline \multicolumn{1}{l}{ CCASHP Results } & MONTREAL & WINNIPEG & \multicolumn{1}{l|}{ TORONTO } \\
\hline $\begin{array}{l}\text { Energy } \\
\text { Use }\end{array}$ & Post 80 & $30.3 \mathrm{GJ}$ & $47.8 \mathrm{GJ}$ & $25.6 \mathrm{GJ}$ \\
\cline { 2 - 6 } & NZE & $16.8 \mathrm{GJ}$ & $22.4 \mathrm{GJ}$ & $15.3 \mathrm{GJ}$ \\
\hline \multirow{3}{*}{ AOC } & Post 80 & $\$ 1,152$ & $\$ 1,696$ & $\$ 1,006$ \\
\hline & NZE & $\$ 735$ & $\$ 908$ & $\$ 688$ \\
\hline \multirow{3}{*}{ NPV } & Post 80 & $-\$ 41,799$ & $-\$ 49,854$ & $-\$ 39,637$ \\
\cline { 2 - 6 } & NZE & $-\$ 35,631$ & $-\$ 38,181$ & $-\$ 34,367$ \\
\hline
\end{tabular}

Annual energy savings (Fig. 6) are characterized as a percent difference from the CCASHP base case annual energy consumption. For a Post-1980s residence in Winnipeg, the ice storage system was predicted to consume approximately the same amount of energy as the base case, hence $0 \%$ savings.

Annual Operating Cost is defined as the simulated SAHP system operating cost subtracted from the base case operating cost, the results are shown in Fig. 7. Currency is expressed in Canadian Dollars.

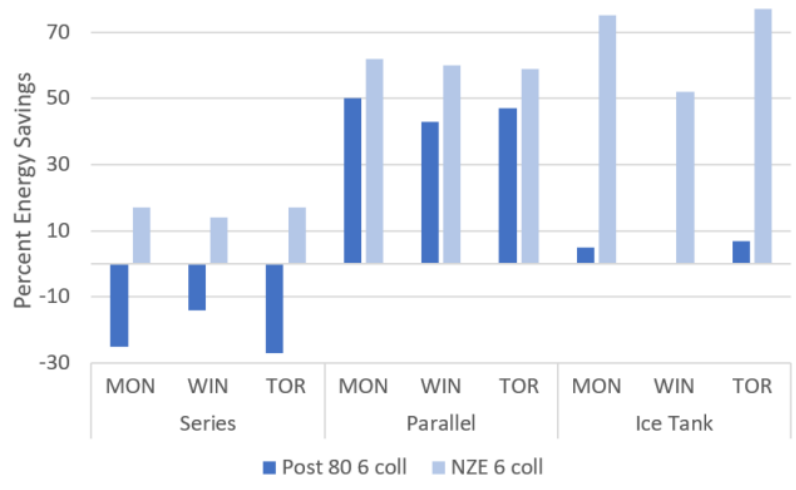

Figure 6. Energy Savings by City, Topology, and Archetype compared to CCASHP System

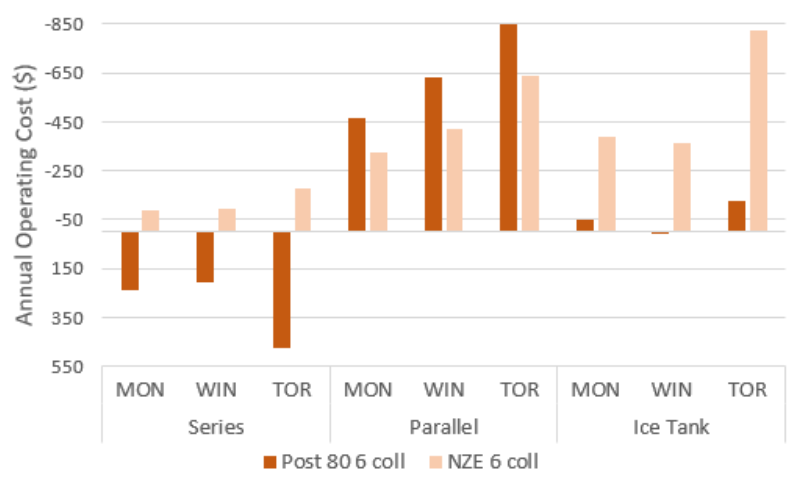

Figure 7. Annual Operating Cost Savings Compared to CCASHP System

The NPV difference plotted in Fig. 8 is the NPV of the simulated system subtracted from the NPV of the CCASHP base case.

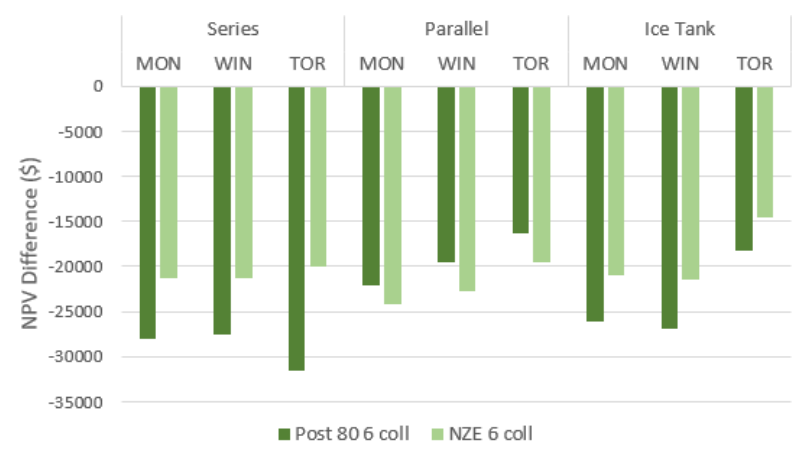

Figure 8. Net Present Value Difference Compared to CCASHP System

As described earlier, the SAHP collectors were sized to 6 panels, based on the Post 1980s archetype demand. This number was also used for the NZE residence, for direct comparison, though likely oversized. The results for a 3 and 6 collector system are compared for a NZE archetype in Montreal in Fig. 9, to evaluate the sensitivity of that assumption. No changes to the storage tank or heat pump capacity were made, as the systems have little sensitivity to these factors with such a small heating demand. The NPV is shown to decrease greatly, while savings only slightly.

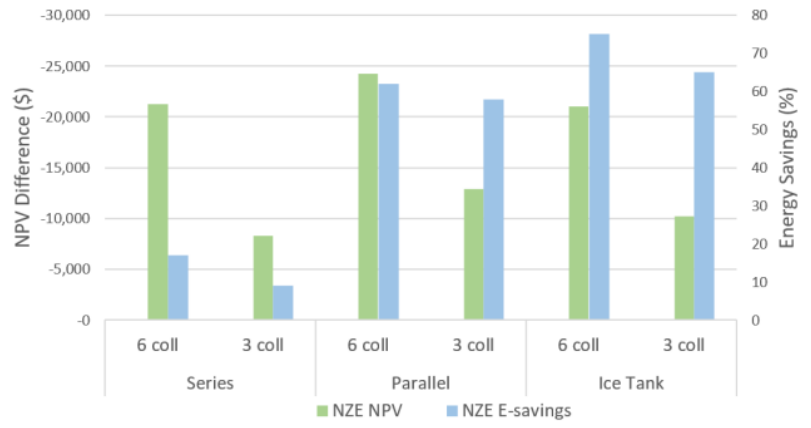

Figure 9. NZE Residence from 6 to 3 Collectors

\section{Discussion}

The three topologies were simulated in three cities (Montreal, Winnipeg, and Toronto) and two housing archetypes (Post-1980s and Net Zero Energy residences). The topologies are compared using a cold climate heat pump system as a base case. The annual energy consumption, annual operating costs, and net present values are the factors compared. This section will discuss observed trends and explanations of the results.

\subsection{Energy Savings and Operating Cost}

The configuration with the best general performance was found to be the parallel topology. In all cases, the parallel system provided significant energy savings when compared to a CCASHP system. The energy savings show little variation by city with a range of $59 \%$ in Toronto to $62 \%$ in Montreal for NZE residences, and 43\% in Winnipeg to $50 \%$ in Montreal for Post-1980s 
residences. The annual operating cost was also reduced in all cities and archetypes relative to the base case. While energy savings were highest in Montreal, operating cost savings were highest in Toronto, with Montreal providing the least overall savings.

The series system provided little energy savings and annual operating cost reduction in the case of Net Zero Energy homes in all cities considered. The energy savings varied from $14 \%$ in Winnipeg to $17 \%$ in Toronto and Montreal. While their energy savings are equal, operating cost savings were higher in Toronto. However, its performance was inferior to a CCASHP in Post-1980s residences in all cities.

The ice storage system results varied by the widest margin among all systems. For the NZE residences, the ice storage system provided significant energy savings. The system exceeded the energy savings of the parallel system in Montreal and Toronto, reaching 75\% and 77\% respectively, while closely approaching them in Winnipeg at $52 \%$. Operating cost savings showed significant variation ranging from $-362 \$$ in Winnipeg to $-824 \$$ in Toronto. For Post-1980s residences, the ice storage provided only marginal savings in Montreal and Toronto, and no savings in Winnipeg.

\subsection{Energy Trends and Observations}

For the Post-1980s residence, there is a clear trend by topology. The series system is outperformed by a CCASHP, while the ice storage system provides marginal savings, if any. The parallel topology alone provides significant annual savings in energy and operating cost. Energy savings and operating costs for each topology follow similar trends by archetype with slight variations by city. As seen in the series and parallel topologies, a system with high energy savings in one city may provide more cost savings in another. This is because of the large difference in heating demand between each city. Percent energy savings in Winnipeg were often lower than Montreal due to the colder climate, however the actual savings in GJ were larger because of Winnipeg's significantly higher load (Table 1). Even more significantly, cost savings were around twice as large in Toronto across all cities, despite having similar energy savings to Montreal, due to the high cost of electricity.

The results for the series system may seem initially unintuitive. The series and CCASHP systems share very similar structure, the main difference being the heat pump sourcing energy from either solar heat or air respectively. As the series system does not use hybrid collectors, it can only source heat from solar. During periods of low solar availability in the winter, the series system must often switch to an auxiliary source, while the CCASHP can continue to operate. In the NZE residence, the loads are reduced to a point where the solar availability and thermal storage capacity are sufficient. This allows the series topology to slightly outperform the CCASHP.
Conversely, one of the reasons for the superior performance of the parallel system is clear. As described earlier, the primary drawback of the series system is that the energy intensive heat pump must be activated to access solar resource. The CCASHP shares this constraint, limiting its efficiency. From fall to spring, there are days where a simple solar thermal loop would be enough to meet the load, rather than an energy intensive heat pump, because of the high peak temperatures the collectors can reach (and the load balancing effect of the system's storage capacity). The ability of the parallel system to directly charge the storage tank with solar energy is one of its strengths.

The ice storage system shares this strength; however, it fails to provide significant savings compared to the CCASHP in a Post-1980s residence, being greatly outperformed by the parallel topology. The impact of the solar thermal loop is revealed in the great difference in performance between the Post-1980s and NZE archetypes. In a NZE residence, the ice storage system performs similarly to the parallel system. This is because accessing solar resource without the heat pump is sufficient to meet the low space heating demand of a NZE residence for many hours of the year.

In the lower load cities of Montreal and Toronto with a NZE archetype, the ice storage system provides significantly more savings compared to the parallel system. This is likely due to the ice storage typology's ability to bypass the storage tank entirely and meet load directly. In the shoulder seasons, the tank will often reach its maximum temperature. In the parallel topology any surplus solar goes to waste, while in the ice storage system the surplus solar from the collectors can be used to meet the heating demand directly. This effect is amplified in Toronto due to the high cost of energy. As annual heating demand increases and solar availability decreases, the tank bypass mode of operation becomes proportionately less relevant, as indicated by the ice storage's drop in performance in Winnipeg. As for the heat pump loops in the ice storage and parallel topologies, the large gap in performance in the Post-1980s residence indicates that the simple CCASHP is superior.

\subsection{NPV}

The sizing of all systems is similar resulting in similar NPV differences values, as shown in Fig. 8. 
Table 4 - NPV Difference by City and Residence

\begin{tabular}{|l|l|l|l|}
\hline \multirow{4}{*}{ Series } & & Post-80s & NZE \\
\cline { 2 - 4 } & Montreal & -28000 & -21200 \\
\cline { 2 - 4 } & Winnipeg & -27500 & -21200 \\
\cline { 2 - 4 } & Toronto & -31500 & -20000 \\
\hline \multirow{4}{*}{$\begin{array}{l}\text { Parallel } \\
\text { Sce }\end{array}$} & Montreal & -22000 & -24200 \\
\cline { 2 - 4 } & Winnipeg & -19600 & -22700 \\
\cline { 2 - 4 } & Toronto & -16300 & -19500 \\
\cline { 2 - 4 } & Montreal & -26000 & -20900 \\
\cline { 2 - 4 } & Winnipeg & -26800 & -21400 \\
\cline { 2 - 4 } & Toronto & -18100 & -14500 \\
\hline
\end{tabular}

In all cases, even when the SAHP systems provided energy and annual cost savings, their NPV was still inferior to that of the CCASHP base case. The benefits of the collector and heat pump did not initially outweigh their impact to the cost of the system. While the energy savings mean that the system has a payback time, it is often longer than the life cycle of the system components themselves.

Despite its poor performance, the series system has a similar NPV to the ice storage system in Montreal and Winnipeg due it is ability to perform optimally with a small heat pump. However, this benefit of the series system is outweighed by the low cost of energy in Toronto. For the NZE archetype, the NPV difference is lowest in Toronto with the Ice Storage system, due to its ability to avoid using the heat pump and meet load directly. It must be noted that, with more detailed sizing, the parallel and ice storage system may also perform adequately in a NZE residence with a slightly smaller heat pump, though still likely larger than the series system. This would slightly reduce their NPV. The parallel system is unique in that its NPV is improved with the higher heating demand of the Post-1980s residence. The cost difference from the base case is lowest in Toronto with the Parallel topology. As sizing does not change, the reason for this increase is that the system can provide proportionately greater savings when meeting a larger load, in a city with costly energy.

While the parallel system gives excellent savings in both energy and operating cost, the initial investment remains as its main weakness. The primary contributor to the high capital cost of SAHPs is the collector array. Therefore, the number of collectors should be minimized while maintaining performance. As discussed earlier, sizing ratios indicate that for a NZE residence, 3 collectors $\left(8.6 \mathrm{~m}^{2}\right)$ are sufficient rather than $6\left(17.2 \mathrm{~m}^{2}\right)$. The results are plotted in Fig. 9, indicating the change in NPV and energy savings. The series system energy savings dropped $8 \%$, while the NPV difference dropped from $21,300 \$$ to $8,800 \$$. This value is especially low due to the series system alone being sized with a smaller heat pump. The ice storage system energy savings decreased similarly by $10 \%$, while the NPV difference dropped from $21,000 \$$ to $10,200 \$$. The parallel system energy savings dropped by only $4 \%$, while decreasing the NPV differences from $24,200 \$$ to $12,900 \$$. Residences with low heating demand can greatly reduce their required initial investment for a SAHP by decreasing their collector area. The results show that this can be done while still providing significant energy savings.

\section{Conclusion}

Three SAHP system topologies were compared to a cold climate heat pump base case across three Canadian cities and two building archetypes. The series topology showed minor energy and operating cost savings in a NZE residence. The parallel topology showed significant energy and operating cost savings in both the Post 80's and NZE archetypes. Both topologies had poorer NPV values when compared to a CCHP, in all cases.

This work serves as a high-level analysis of common SAHP configurations. Work remains to be done in several aspects. To better understand the system's performance trends, simulations should be performed across a wider number of Canadian cities.

The system sizing used in this work is a rough approximation. A complete optimization of heat pump, storage tank size, and collector area has yet to be done. Additionally, the sizing used in this work was specific to Montreal. Location specific sizing will be a next step in improving the accuracy of these models. This transition from high level analysis to more detailed work will involve moving to a more detailed building simulation software.

A key issue identified with SAHP systems is their relatively high capital costs. Capital cost is also the portion of this work with the highest uncertainty. Future work should more accurately estimate the capital costs of these systems, along with their life cycles. This information would then be used to calculate more precise system payback times and NPV. This would allow for work that determines what is required for the savings offered by SAHPs to outweigh their initial investment. Additionally, a detailed GHG emissions calculation should be conducted to estimate the impacts of each typology.

\section{References}

[1] Canada's Secondary Energy Use (Final Demand) and GHG Emissions by Energy Source | Natural Resources Canada n.d.

http://oee.nrcan.gc.ca/corporate/statistics/neud/d $\mathrm{pa} /$ showTable.cfm?type $=$ HB\&sector $=$ aaa\&juris $=$ ca\&rn $=1 \&$ page $=0$ (accessed November 25 , 2019).

[2] Ürge-Vorsatz D, Cabeza LF, Serrano S, Barreneche C, Petrichenko K. Heating and cooling energy trends and drivers in buildings. Renew Sustain Energy Rev 2015;41:85-98. https://doi.org/10.1016/j.rser.2014.08.039. 
[3] Heat Pump Market Size \& Share, Growth | Industry Report, 2019-2025. Gd View Res 2019. https://www.grandviewresearch.com/industryanalysis/heat-pump-market (accessed November 2, 2020).

[4] Freeman TL, Mitchell JW, Audit TE. Performance of combined solar-heat pump systems. Sol Energy 1979;22:125-35. https://doi.org/10.1016/0038-092X(79)90096-3.

[5] NRCAN. Paving the Road to 2030 and Beyond: Market transformation road map for energy efficient equipment in the building sector. Energy Mines Minist Conf 2018.

[6] Manton BE, Mitchell JW. A Regional Comparison of Solar, Heat Pump, and SolarHeat Pump Systems. 1982.

[7] Chandrashekar M, Le NT, Sullivan HF, Hollands KGT. A comparative study of solar assisted heat pump systems for canadian locations. Sol Energy 1982;28:217-26. https://doi.org/10.1016/0038092X(82)90160-8.

[8] Carbonell D, Haller MY, Frank E. Potential benefit of combining heat pumps with solar thermal for heating and domestic hot water preparation. Energy Procedia, vol. 57, Elsevier Ltd; 2014, p. 2656-65. https://doi.org/10.1016/j.egypro.2014.10.277.

[9] Engineering Climate Datasets - Climate Environment and Climate Change Canada n.d. https:/climate.weather.gc.ca/prods_servs/engine ering_e.html (accessed January 29, 2021).

[10] Tools for industry professionals n.d. https://www.nrcan.gc.ca/energyefficiency/energy-efficiencyhomes/professional-opportunities/tools-industryprofessionals/20596\#wb-cont (accessed January 29, 2021).

[11] Brideau S. Estimating Hourly Heating and Cooling Loads from Monthly Results, 2020 ASHRAE Virtual Conference; 2020.

[12] CER - Canada's Energy Future 2018: Energy Supply and Demand Projections to 2040 n.d. https://www.cer-rec.gc.ca/en/dataanalysis/canada-energyfuture/2018/index.html\#wb-sec (accessed January 31,2021 ).

[13] Hadorn JC. Solar and Heat Pump Systems for Residential Buildings. Berlin, Germany: Wilhelm Ernst \& Sohn; 2015. https://doi.org/10.1002/9783433604830. 